\title{
Ausencia de efectividad del reposo en cama para la ciatalgia
}

Lack of Effectiveness of Bed Rest For Sciatica.

PC Vroomen, MC de Krom, JT Wilmink, et al. N Engl J Med 1999; 340:418-23.

\section{Objetivo}

Estudiar la efectividad del reposo en cama en pacientes con sindrome radicular lumbosacro con severidad suficiente, como para indicarle tratamiento de reposo en cama.

\section{Diseño}

Estudio aleatorizado, controlado y simple ciego.

\section{Lugar}

Centros de Salud de Maastricht y alrededores, Holanda.

\section{Pacientes}

Durante casi dos años se reclutaron 183 pacientes que se presentaban a su médico de cabecera con dolor lumbar irradiado a un miembro inferior debajo del pliegue glúteo. Se eligieron los pacientes que tenían una intensidad de dolor que justificara la indicación de reposo en cama por dos semanas, como tratamiento. Se excluyeron: cirugía de columna previa, embarazo, reclamo compensatorio pendiente de trabajadores, los que no podían ser seguidos (ej.:mudanza), o enfermedad severa coexistente.

\section{Intervención}

A los pacientes que ingresaban al estudio se les realizó una historia clínica completa y una resonancia magnética de la columna lumbar para ver si se identificaban compresiones nerviosas. Si cumplían con los criterios de inclusión (síntomas de ciatalgia y sin indicación de cirugía de columna inmediata) se los asignaba aleatoriamente a dos grupos: reposo en cama durante dos semanas y observación (grupo control). Tenían instrucciones escritas y un diario. Debian reportar todos los días el total de horas de reposo en cama, la intensidad del do-
Lor (escalas de dolor) y el estado funcional. Podían tomar analgésicos para el dolor. El seguimiento fue a las 2, 3 y 12 semanas.

\section{Medición de resultados principales}

El resultado principal primario era la percepción del paciente y del médico del mejoramiento clínico a las 2 y 12 semanas. Los resultados secundarios a evaluar fueron el dolor, el estado funcional, la tasa de ausentismo laboral, y los procedimientos quirúrgicos durante los primeros 6 meses. Los resultados fueron evaluados a las 2 y las 12 semanas en el hospital y a las 3 semanas en su casa; llenando una escala de dolor y otra de funcionalidad. Tanto los investigadores que evaluaban los resultados como los que analizaron los datos desconocían la asignación de los pacientes.

\section{Resultados principales}

Luego de 2 semanas, 64 de los 94 pacientes en el grupo de reposo en cama (70\%) reportaron mejoría, comparado con 59 de los 91 pacientes en el grupo control (65\%) (odds ratio ajustado para la mejoría en el grupo reposo en cama, 1,2 (IC 95\% 0,6-2,3). Luego de 12 semanas, $87 \%$ de los pacientes en ambos grupos reportaron mejoría.

El resultado de la evaluación de la intensidad del dolor, los síntomas molestos, y el estado funcional no revelaron diferencias significativas entre ambos grupos. El ausentismo laboral y las tasas de intervenciones quirúrgicas fueron también similares en ambos grupos.

\section{Conclusiones}

Entre los pacientes con síntomas y signos de sindrome radicular lumbosacro, el reposo en cama no es más efectivo que la observación como estrategia terapéutica.

\section{COMENTARIO}

La lumbalgia es un motivo de consulta bastante frecuente en el consultorio de atención primaria. En la Unidad de Medicina Familiar ocupa el noveno lugar, representando el $3 \%$ del total de las consultas. De los pacientes con lumbalgia aguda sólo el $1,5 \%$ tendrá síntomas de ciatalgia, lo cual implica compromiso de una raiz nerviosa (L5-S1). Una estrategia de manejo ampliamente difundida cuando concurre un paciente con estas características al consultorio es la indicación de reposo en cama por 1 o 2 semanas. Esta alternativa incrementa el ausentismo laboral y predispone a la atrofia muscular, entre otros efectos adversos. Estudios recientes coinciden en que el reposo no es efectivo en el tratamiento de la lumbalgia simple. ${ }^{1-3}$ Este estudio es el primero que compara el reposo con la observación en la ciática, ya que los anteriores comparaban el reposo con otros tratamientos farmacológicos o invasivos (como la anestesia epidural ${ }^{4}$ ).

Es importante mencionar algunos puntos acerca del mismo que no pa- recen invalidar los resultados. El trabajo presenta un sesgo de selección* ya que los pacientes fueron vistos por su médico de cabecera quien los seleccionaba para el reclutamiento, derivando, probablemente, a los pacientes con una presentación clínica más seria. Esto limita tal vez la validez externa* y lo hace más aplicable a pacientes con síntomas más claros y severos. También se observó algo interesante, llamado sesgo de expectativa: el subgrupo de pacientes que había tenido una ciatalgia previa y que fue asignado al grupo reposo reportó una tasa de mejoría mayor que los del grupo control (OR 4,5; IC 95\%, $1,4-15,1)$. Estos pacientes que ya pasaron por los síntomas y las expectativas con el reposo puede que tengan otras efectos. Hay que considerar que esto es un análisis de subgrupo*, con lo que se debe tener cuidado en sacar conclusiones para las que el estudio no fue diseñado. En conclusión, luego de este trabajo se podría dejar de indicar reposo en cama por dos semanas en los pacientes con lumbociatalgia.

*Ver Glosario

Dra. Gabriela A. Lewin

Unidad de Medicina Familiar. Hospital Italiano de Buenos Aires. 